\title{
Introduction to the first issue of World Nutrition for 2021
}

Ted Greiner, Editor-in-Chief

As always, this issue contains several important papers from around the world. Most of them this time deal with health issues related to nutrition. As discussed in an accompanying editorial, Bahrami and I present a first exploratory study of the impact of diet on acid-base balance at cellular and circulatory level, which may have an impact on NCDs, especially cancer. Geyser looks at the impact of the COVID-19 lockdown in London during the Spring of 2020 on food insecurity there, focusing on immigrant groups. Samuel et al. study a neglected group, Nigerian adolescent boys who are school leavers, exploring determinants of their consuming healthy diets and measuring their nutritional status. Kaul et al. examine how well mid upper arm circumference works to measure nutritional status in pregnant women in India and whether it can be an indicator also for high blood pressure in that group. In a literature review, Hettiarachchi and Wijesinghe detail the legal issues related to the drug-food interface, with a focus on situation in Sri Lanka. On the issue of feeding and infant health, in his routine Good Questions editorial, George Kent asks whether infant formula really is much worse than breastfeeding. Mundagowa et al. use qualitative methods to reveal the barriers and facilitators of exclusive breastfeeding in one district in Zimbabwe. Finally, Leshi and Ogundero study the extent to which final year bachelor's students and master's degree students in Nigerian universities are ready to take employment in the fields of nutrition and dietetics. 